\title{
Entrepreneur brings race cars and canaries to cancer research
}

Don Listwin only received what he calls a 'gentleman's B' in his college biology courses. Every other word the former Silicon Valley executive utters is geek-speak: words like 'modular' or 'intersource' or 'platform,' which dazed biologists have to ask him to explain.

But Listwin's ideas for biology are right on the money. He is pouring millions into developing technologies that can identify early-stage cancers - one of the hottest areas of cancer research.

Listwin's mother died of ovarian cancer two years ago and his father is a cancer survivor. After spending more than a decade at the helm of hightech firms such as Cisco Systems and Openwave, Listwin retired last year at 45 . Now he devotes much of his time and money to promoting early cancer detection. "When my mother was suffering from ovarian cancer, I spent years researching this disease, and learned that the key to treating cancer was to catch it early," he says.

In the past two years, Listwin has pledged more than $\$ 15$ million to researchers at the Fred Hutchinson Cancer Research Center, Stanford University and the University of California, San Francisco. He spent another $\$ 1$ million to set up the Canary Fund-named for the birds that warn miners of toxic fumes - to support early detection research. A lover of fast cars, Listwin also bought the San Jose Grand Prix, and is auctioning off rides around the San Jose race track in a real stock car to raise funds.

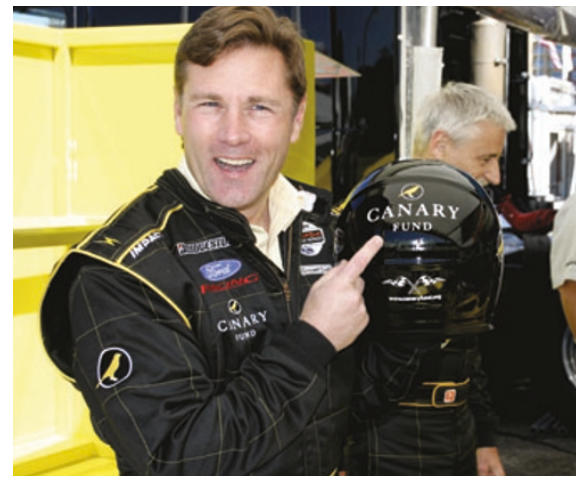

Bird's-eye view: Non-biologist Don Listwin says early detection is the key to combating cancer.

The US spends nearly $\$ 10$ billion each year on cancer research, most of it for developing treatments or for patient care. But scientists are increasingly focusing on detection.

High-throughput technologies such as gene expression profiling and proteomic analysis can detect cancer biomarkers in blood and urine. Hundreds of 'molecular markers' of tumor formation and progression have been reported in the scientific literature, but little has been done to translate these into reliable and cost-effective diagnostic tests. Despite the number of known markers, gene expression or proteomics data from one study or patient population can rarely be applied to another.

Through the Canary Fund, Listwin says he plans to use the skills he honed in building the internet during the 1990s to develop computer systems that can standardize data analysis. A large proportion of the grants will go to biotechnology companies and computer scientists. Listwin - with advice from Nobel Laureate Lee Hartwell and others on the fund's scientific advisory board-hand-picks recipients of the fund's grants, which now amount to $\$ 2$ million.

$\mathrm{He}$ also plans to speed up translation of the technologies to the clinic through open-source initiatives, which were instrumental in developing the Linux computer operating system.

"Right now, researchers have to hoard all their information until it is publishable," Listwin says. Easing the financial pressure on scientists would allow them to share and modify each other's technologies. One company he plans to support is LabKey Software, which builds free open-source systems that allow scientists to collect, process and share data.

Listwin is also working with the US Food and Drug Administration to set standards for evaluating detection methods. The agency does not yet have ways to assess the effectiveness of early diagnostic technologies, according to Larry Kessler, director of the agency's Office of Surveillance and Biometrics. For example, it's not clear how early, or with what specificity or sensitivity, the assay should be able to detect tumor markers.

Kris Novak, San Francisco

\section{US demands antiprostitution pledge from AIDS groups}

The Bush administration in June announced that US-based AIDS groups working in other countries must formally oppose prostitution in order to win federal funds for their programs.

Only foreign organizations acting overseas were previously required to make the antiprostitution pledge, under legislation authorizing the five-year $\$ 15$ billion President's Emergency Plan for AIDS Relief (PEPFAR) (Nat. Med. 9, 808; 2003). PEPFAR mandates that US funds only go to groups that adopt "a policy explicitly opposing prostitution and sex trafficking."

The policy shift had been anticipated since September 2004, when the US Department of Justice ruled that applying PEPFAR's pledge conditions to domestic charities did not breach US constitutional rights of free speech. In May, 200 US-based nonprofit groups wrote a letter against the mandate, arguing that ideological arguments should not influence evidence-based public health interventions.

Roslyn Matthews, a spokesperson for the US Agency for International Development
(USAID) says the policy does not preclude groups from providing services to high-risk populations, including sex workers.

But an official antiprostitution policy might further alienate a high-risk population already on the fringe. "The credibility that organizations and individuals must cultivate to gain the trust of this population would be dramatically undermined," says Judith Auerbach, vice president of public policy at the American Foundation for AIDS Research.

The pledge erodes ground-level HIV prevention programs, adds Jodi Jacobson, executive director of the Center for Health and Gender Equity, which monitors US health policy around the world. "It's grossly immoral and goes against human rights and bioethical principles."

Already, a few groups are preemptively pulling the plug on their programs. For instance, the Urban Sector Group in Cambodia decided last November to discontinue English lessons for sex workers. "The English skills enabled [sex workers] to negotiate safer sex and begin moving out of sex work," says Alice Miller, assistant professor of public health at Columbia University. "But is that the same thing as promoting prostitution?"

Programs that are most likely to lose funding are those that blend public health interventions with human rights work, even though they have been among the most successful in preventing HIV/AIDS, says Jacobson. India's 60,000-member Durbar Mahila Samanay Committee, for instance, simultaneously promotes HIV/AIDS peer education and sex worker advocacy for equal worker rights. More than 3,000 members of the group in May protested the antiprostitution pledge. The Brazilian government also in May refused \$40 million from USAID on grounds that the pledge does not stem from scientific evidence.

Nonprofit groups might mount legal action opposing the pledge. But until then, Jacobson says, "my only projection is one of despair."

Paroma Basu, Madison 